Article

\title{
Thermal Characterization and Modelling of AlGaN-GaN Multilayer Structures for HEMT Applications ${ }^{\dagger}$
}

\author{
Lisa Mitterhuber *, René Hammer, Thomas Dengg and Jürgen Spitaler(i) \\ Materials Center Leoben Forschung GmbH, Roseggerstrasse 12, 8700 Leoben, Austria; \\ rene.hammer@mcl.at (R.H.); thomas.dengg@mcl.at (T.D.); juergen.spitaler@mcl.at (J.S.) \\ * Correspondence: lisa.mitterhuber@mcl.at \\ † This paper is an extended version of our conference paper "Thermal Investigation of AlGaN-GaN Multilayer \\ Structures", 2019 25th International Workshop on Thermal Investigations of ICs and Systems (THERMINIC), \\ Lecco, Italy, 2019.
}

Received: 30 March 2020; Accepted: 29 April 2020; Published: 9 May 2020

\begin{abstract}
To optimize the thermal design of AlGaN-GaN high-electron-mobility transistors (HEMTs), which incorporate high power densities, an accurate prediction of the underlying thermal transport mechanisms is crucial. Here, a HEMT-structure $\left(\mathrm{Al}_{0.17} \mathrm{Ga}_{0.83} \mathrm{~N}, \mathrm{GaN}, \mathrm{Al}_{0.32} \mathrm{Ga}_{0.68} \mathrm{~N}\right.$ and AlN on a Si substrate) was investigated using a time-domain thermoreflectance (TDTR) setup. The different scattering contributions were investigated in the framework of phonon transport models (Callaway, Holland and Born-von-Karman). The thermal conductivities of all layers were found to decrease with a temperature between $300 \mathrm{~K}$ and $773 \mathrm{~K}$, due to Umklapp scattering. The measurement showed that the AlN and GaN thermal conductivities were a magnitude higher than the thermal conductivity of $\mathrm{Al}_{0.32} \mathrm{Ga}_{0.68} \mathrm{~N}$ and $\mathrm{Al}_{0.17} \mathrm{Ga}_{0.83} \mathrm{~N}$ due to defect scattering. The layer thicknesses of the HEMT structure are in the length scale of the phonon mean free path, causing a reduction of their intrinsic thermal conductivity. The size-effect of the cross-plane thermal conductivity was investigated, which showed that the phonon transport model is a critical factor. At $300 \mathrm{~K}$, we obtained a thermal conductivity of $(130 \pm 38) \mathrm{Wm}^{-1} \mathrm{~K}^{-1}$ for the $(167 \pm 7) \mathrm{nm}$ thick $\mathrm{AlN},(220 \pm 38) \mathrm{Wm}^{-1} \mathrm{~K}^{-1}$ for the $(1065 \pm 7) \mathrm{nm}$ thick $\mathrm{GaN},(11.2 \pm 0.7) \mathrm{Wm}^{-1} \mathrm{~K}^{-1}$ for the $(423 \pm 5) \mathrm{nm}$ thick $\mathrm{Al}_{0.32} \mathrm{Ga}_{0.68} \mathrm{~N}$, and $(9.7 \pm 0.6) \mathrm{Wm}^{-1} \mathrm{~K}^{-1}$ for the $(65 \pm 5) \mathrm{nm}$ thick $\mathrm{Al}_{0.17} \mathrm{Ga}_{0.83} \mathrm{~N}$. Respectively, these conductivity values were found to be $24 \%, 90 \%, 28 \%$ and $16 \%$ of the bulk values, using the Born-von-Karman model together with the Hua-Minnich suppression function approach. The thermal interface conductance as extracted from the TDTR measurements was compared to results given by the diffuse mismatch model and the phonon radiation limit, suggesting contributions from inelastic phonon-scattering processes at the interface. The knowledge of the individual thermal transport mechanisms is essential for understanding the thermal characteristics of the HEMT, and it is useful for improving the thermal management of HEMTs and their reliability.
\end{abstract}

Keywords: AlGaN-GaN HEMT; TDTR; thermal conductivity; thermal interface resistance; size effect; phonon transport mechanisms

\section{Introduction}

The ability of gallium nitride $(\mathrm{GaN})$ to form heterojunctions can be used to fabricate high-electron-mobility transistors (HEMTs). Aluminium gallium nitride (AlGaN)-GaN-based HEMTs offer high carrier concentration $\left(\sim 1013 \mathrm{~cm}^{-2}\right.$ [1]) and high electron mobility $\left(2000 \mathrm{~cm}^{2} / \mathrm{Vs}\right.$ [2]), resulting in a high current density and a low channel resistance. These properties offer great potential in the power amplifier technology due to their high-power and high-frequency performance. Thus, these devices are attractive for communication, radar and space applications [3]. The high output 
power density in the AlGaN-GaN-HEMT also allows further miniaturization of the device with gate lengths down to $80 \mathrm{~nm}$ [4]. However, this high-power density leads to significant self-heating, which decreases the device performance. Thus, to have reliable and long-lasting devices, a thorough thermal management is becoming increasingly relevant [5-7]. Therefore, thermal characterization and modelling are essential in order to guarantee an efficient heat removal from the heterojunction. Thermal bottlenecks that have to be considered in GaN-based HEMTs are: (i) the reduced thermal conductance of transition layers (here: AlGaN) [8], (ii) the heat transport across interfaces [9], and (iii) the reduced thermal conductivity due to phonon-scattering processes [10,11].

The information gained by this study allows thermal engineering of GaN-based HEMTs and, hence, consequent improvement in thermal management to achieve reliable and long-lasting devices. The paper has three major topics:

Firstly, we systematically investigated a material stack of a high-electron-mobility transistor (HEMT) on a silicon (Si) substrate. Both the thermal properties of the constituent materials and their thermal interface conductance were obtained simultaneously by using a time-domain thermoreflectance (TDTR) measurement setup. In literature, the thermal investigations of the individual materials of the HEMT stack can be found. For example, Chen et al. measured the intrinsic thermal conductivity of AlN [12]. Park and Bayram [13] were investigating GaN grown on different substrates to extract the influence of dislocations on the thermal behaviour. Lui and Balandin [14] did thermal investigations on $\mathrm{Al}_{x} \mathrm{Ga}_{1-\mathrm{x}} \mathrm{N}$ alloys. Other studies investigated the whole device and reported on the temperature field, such as Chatterjee et al. [15]. Lundh et al. [16] used Raman spectroscopy and thermoreflectance thermal imaging to experimentally obtain the lateral and vertical steady-state operating temperature of an AlGaN-GaN HEMT. In this study, we demonstrate a thermal investigation of the holistic HEMT stack, including the thermal conductivities of each layer and the interfaces.

Secondly, the intrinsic thermal conductivity and the mean free path of the phonons were extracted by TDTR measurements at different temperatures. Three different phonon transport models obtained the different phonon scattering mechanisms: the Callaway, Holland, and Born-von-Karman (BvK) models. We describe the significant differences and assumptions of these models. Recently, it was recognised that the cumulative sum over all phonon contributions from the smallest mean free paths up to infinity constitutes a complete description of the bulk thermal conductivity but is particularly powerful when size effects are being investigated. For instance, Yang and Dames [17] analysed phonon transport models for bulk Si and Si nanowires. Regner et al. [18] were also determining the effect of different phonon transport models in terms of accumulated thermal conductivity. In our work, we evaluated the phonon scattering times within the said phonon transport models on the materials of the HEMT stack, based on our temperature-dependent experimental results. We show that the availability of temperature-dependent data is crucial for the analysis of the different scattering contributions.

Thirdly, we revised the calculation of the size effect of the layers with three different approaches: first, with a suppression function approach as introduced by Hua and Minnich [19]. Second, by a common approach using the accumulation of thermal conductivity over the boundary scattering [20]. Third, we determined the size effect via a phonon hydrodynamic equation as proposed by Gua and Wang [21]. All three approaches are compared for predicting the size-dependent cross-plane thermal conductivity.

\section{Materials and Methods}

The investigated device was an ungated GaN-based HEMT consisting of an AlGaN-GaN heterostructure. The layers were produced by a metal-organic chemical vapour deposition (MOCVD) process [22]. The AlGaN-GaN heterostructure includes a Si (111) substrate, a $2 \mathrm{~nm}$ thick silicon nitride layer, a $(167 \pm 7) \mathrm{nm}$ thick aluminium nitride $(\mathrm{AlN})$ nucleation layer, a $(423 \pm 5) \mathrm{nm}$ thick $\mathrm{Al}_{0.32} \mathrm{Ga}_{0} \cdot{ }_{68} \mathrm{~N}$ transition layer, a $(1065 \pm 7) \mathrm{nm}$ thick $\mathrm{GaN}$ buffer layer, and a $(65 \pm 5) \mathrm{nm}$ thick $\mathrm{Al}_{0.17} \mathrm{Ga}_{0 \cdot 83} \mathrm{~N}$ top barrier layer. A cross-sectional scanning electron microscope (SEM) investigation determined the thickness of all layers (see Figure 1 -right-hand side). The $\mathrm{Al}_{\mathrm{x}} \mathrm{Ga}_{1-\mathrm{x}} \mathrm{N}$ layer composition was 
analysed via X-ray diffraction [22]. At the interface between the buffer and top barrier layer, lies the heterojunction of the HEMT, where the two-dimensional electron gas channel is formed. To gain an in-depth knowledge of the heat transport mechanisms within HEMTs, four samples, encompassing different number of sublayers of the overall heterostructure (see Figure 1 Samples A-D), were produced and thermally characterized.
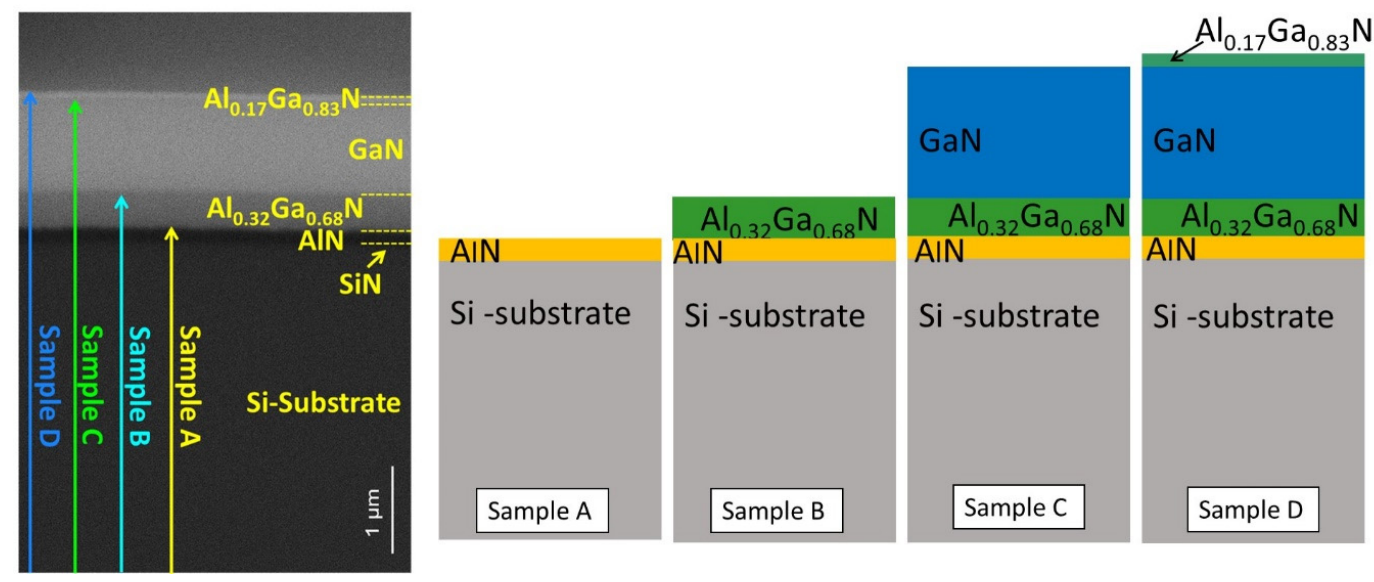

Figure 1. On the left-hand side, the SEM image of the cross-section of the AlGaN-GaN heterostructure (Sample D) is shown. The schematic of the studied AlGaN-GaN-based high-electron-mobility transistor (HEMT) structures is visualised on the right (Samples A-D).

The cross-plane thermal characterization of the four samples A to D was accomplished with a TDTR measurement (PicoTR, Netzsch [23]), which was also used in previous experiments [24]. An integrated oven with a continuous nitrogen flow allowed the measurements to be performed in the range of $300 \mathrm{~K}$ to $773 \mathrm{~K}$. The samples A-D were investigated subsequently (see Figure 1). A $100 \mathrm{~nm}$-thick platinum (Pt) layer covered all samples as a transducer. The TDTR setup used was a pump-probe technique, where the pump beam had a wavelength of $1550 \mathrm{~nm}$, a spot radius of $45 \mu \mathrm{m}$ and a pulse energy of $25 \mathrm{~mW}$. The pump beam and the probe beam had a pulse width of $0.5 \mathrm{ps}$. For the purpose of lock-in detection, the pump beam was modulated at $200 \mathrm{kHz}$. The pump beam was focused on the top face of the Pt-layer, and the probe beam was focused on the same position. The temperature change caused by the pump beam was monitored by the probe beam, with a wavelength of $775 \mathrm{~nm}$, by using the two-colour thermoreflectance principle. The probe beam was electrically time delayed to the pump beam with a picosecond time resolution. This time resolution allowed an analysis of both the thermal conductivity of the individual layers and the thermal interface conductance. These thermal properties were determined by fitting the phase delay to an analytical heat conduction model [25]. The phase signal over time showed a max. noise of $1^{\circ}$ and the uncertainty of the measurements were calculated according to Yang et al. [26].

\section{Results}

The thermal conductivity $(\kappa)$ of the constituent materials and thermal interface conductance were measured by the TDTR. The phase signal of the lock-in amplifier of the TDTR was analysed by using the analytical heat flow model of the multi-layered structures as proposed by Cahill [25]. The thickness (see Figure 1) and the volumetric heat capacity of all materials and kof the Si substrate were used as input for the calculations. All temperature-dependent thermophysical properties of $\mathrm{Si}$ were taken from the literature [27,28]. The heat capacity of AlN and GaN at $300 \mathrm{~K}$ was $2.67 \mathrm{MJm}^{-3} \mathrm{~K}^{-1}$ and $2.63 \mathrm{MJm}^{-3} \mathrm{~K}^{-1}$. These values and their temperature dependency were taken from [29] and [30], respectively. By using the rule of mixture, the heat capacity of $2.65 \mathrm{MJm}^{-3} \mathrm{~K}^{-1}$ for $\mathrm{Al}_{0.32} \mathrm{Ga}_{0 \cdot 68} \mathrm{~N}$ was calculated. A 4-point probe measurement captured the electrical sheet resistance of the Pt-transducer layer. The thermal conductivity $(\kappa)$ of the Pt transducer was determined to be $14 \mathrm{~W} / \mathrm{mK}$ according to the Wiedemann-Franz law. 
Starting from Sample A, $\kappa$ of the AlN layer $\left(\kappa_{A l N}\right)$ and the thermal interface conductance between $\mathrm{Pt}$ and AlN were measured via TDTR. These values were used as input parameters for Sample B, which provided the $\kappa$ for the alloy $\mathrm{Al}_{0.32} \mathrm{Ga}_{0} \cdot{ }_{68} \mathrm{~N}$ and the corresponding thermal interface conductance. Consequently, for the analysis of Sample $\mathrm{C}$ we used the results from Sample B. The same procedure was applied for Sample D, using the results obtained from Sample C. [31]

The temperature-dependence of $\kappa_{A l N}$ for the $(167 \pm 7) \mathrm{nm}$ thick AlN of Sample A is presented in Figure 2a. $\kappa_{\text {AlN }}$ decreased from $(130 \pm 38) \mathrm{Wm}^{-1} \mathrm{~K}^{-1}$ at $300 \mathrm{~K}$ to $(16 \pm 13) \mathrm{Wm}^{-1} \mathrm{~K}^{-1}$ at $773 \mathrm{~K}$. Our results, as can be seen, are half of the values reported by Slack et al. [32]. Such a difference potentially can be explained by size effects (as investigated in more detail below) and different defect densities, stemming from different growth processes, which might reduce the thermal conductivity. Slack et al. [32] investigated a single AlN crystal with a thickness of $3 \mathrm{~mm}$, grown from high-purity AlN powder by vapour-phase transport.
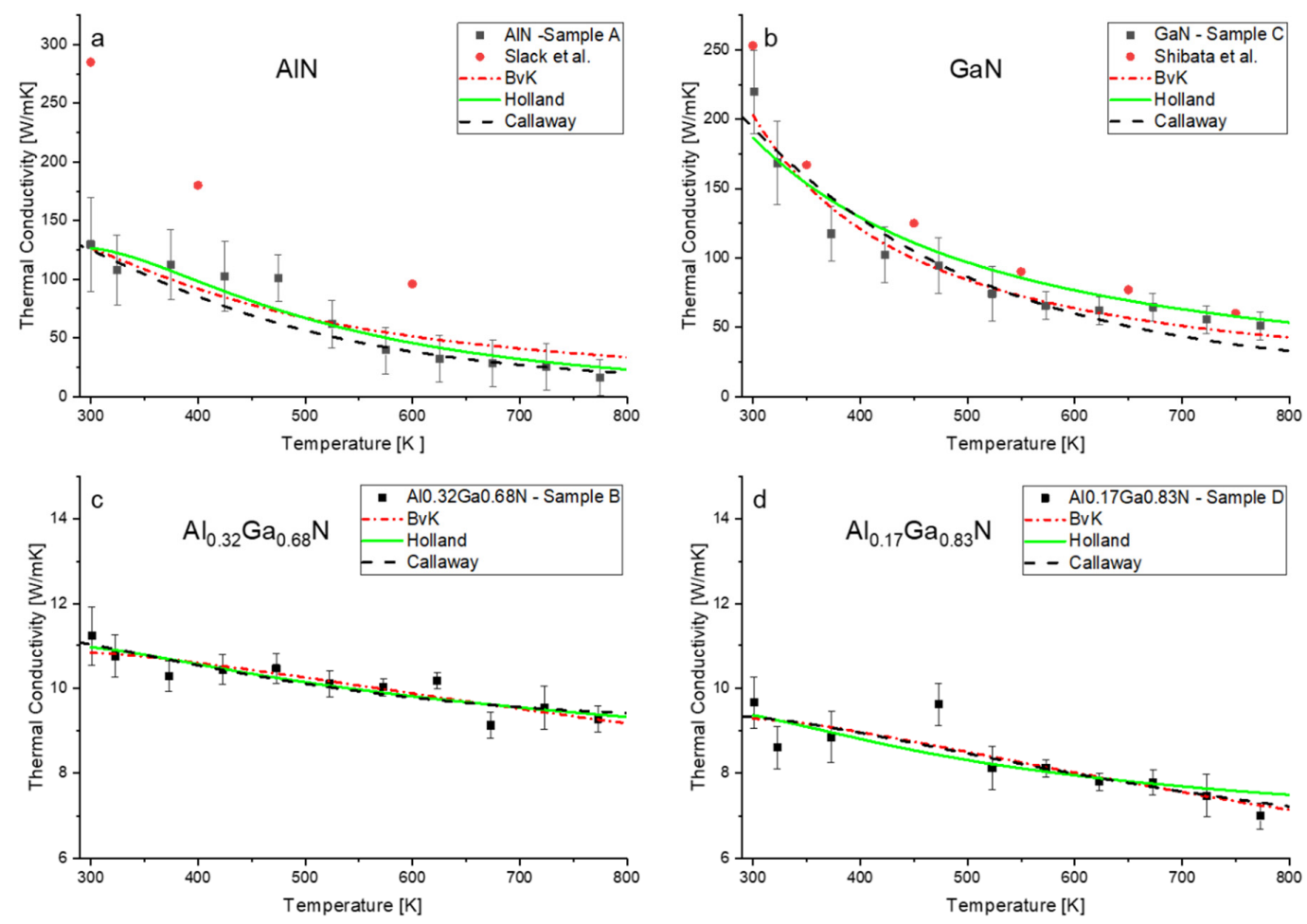

Figure 2. Measured and calculated thermal conductivities as a function of temperature. Measured $\kappa$ of (a) $\mathrm{AlN}$, (b) $\mathrm{GaN}$, (c) $\mathrm{Al}_{0.32} \mathrm{Ga}_{0.68} \mathrm{~N}$, and (d) $\mathrm{Al}_{0.17} \mathrm{Ga}_{0.83} \mathrm{~N}$ are marked as black squares, while thermal conductivities from literature are shown as red circles. Solid lines depict the models for lattice thermal conductivities, describing the scattering processes in the materials (dotted-dashed red: Born-von Karman, solid green: Holland and dashed black: Callaway model).

Figure $2 \mathrm{c}$ shows the cross-plane thermal conductivity of the $(423 \pm 5) \mathrm{nm} \mathrm{Al}_{0.32} \mathrm{Ga}_{0.68} \mathrm{~N}$ (obtained from the measurements on Sample B). The previous results of $\kappa_{A l N}$ (obtained from Sample A) served as an input parameter. The $\mathrm{Al}_{0.32} \mathrm{Ga}_{0.68} \mathrm{~N}$ layer had a thermal conductivity of (11.2 \pm 0.7$)$ $\mathrm{Wm}^{-1} \mathrm{~K}^{-1}$ at $300 \mathrm{~K}$. $\kappa$ of $\mathrm{Al}_{0.32} \mathrm{Ga}_{0.68} \mathrm{~N}$ was one order of magnitude smaller than $\kappa_{A I N}$, due to the phonon scattering processes from defects/ alloying elements [33]. The thermal conductivity of the $(65 \pm 7) \mathrm{nm} \mathrm{Al}_{0.17} \mathrm{Ga}_{0.83} \mathrm{~N}$ of Sample D was $(9.7 \pm 0.6) \mathrm{Wm}^{-1} \mathrm{~K}^{-1}$ at $300 \mathrm{~K}$ and decreased to $(7.0 \pm 0.3)$ $\mathrm{Wm}^{-1} \mathrm{~K}^{-1}$ at $773 \mathrm{~K}$ (see Figure $2 \mathrm{~d}$ ). In our case, the thermal conductivity of $\mathrm{Al}_{0.17} \mathrm{Ga}_{0.83} \mathrm{~N}$ was even lower than that of $\mathrm{Al}_{0.32} \mathrm{Ga}_{0} \cdot{ }_{68} \mathrm{~N}$, explainable by their difference in layer thickness (enhanced boundary scattering). The temperature-dependence of the thermal conductivity of these alloys was much weaker than that obtained for $\kappa_{A l N}$. This behavior was in agreement with the results reported by Daly [34], who investigated $\mathrm{Al}_{0.18} \mathrm{Ga}_{0.82} \mathrm{~N}, \mathrm{Al}_{0.20} \mathrm{Ga}_{0.80} \mathrm{~N}$, and $\mathrm{Al}_{0.44} \mathrm{Ga}_{0.56} \mathrm{~N}$. 
Figure 2c shows the thermal conductivity of the GaN film $\left(\kappa_{G a N}\right)$ from Sample C. $\kappa_{G a N}$ decreases from $(220 \pm 38) \mathrm{Wm}^{-1} \mathrm{~K}^{-1}$ at $300 \mathrm{~K}$ to $(51 \pm 9) \mathrm{Wm}^{-1} \mathrm{~K}^{-1}$ at $773 \mathrm{~K}$. This value was similar to the findings reported by Shibata et al. [35] for a GaN film grown by a hydride-vapour phase epitaxy process (here, the MOCVD process).

This work aims to clarify the origin of the reduced thermal conductivity of all those layers, within the HEMT layer stack, by applying different phonon transport and boundary models (see below).

The thermal interface conductance between Pt and AlN (obtained from the TDTR measurements of Sample A) increased with temperature (red squares in Figure 3a). Above the Debye temperature of $\mathrm{Pt}(240 \mathrm{~K}$ [36]), this increase indicates a dominating inelastic scattering of phonons at the interface [37]. The temperature dependence of the thermal boundary conductance is also in line with results obtained from ab-initio molecular dynamics simulations [38], which showed an increase of the thermal conductivity with temperature due to the increase of available spatially localized modes at the interface. In the range of temperatures between $300 \mathrm{~K}$ and $523 \mathrm{~K}$, the value increased from $(269 \pm 54) \mathrm{MWm}^{-2} \mathrm{~K}^{-1}$ to $(380 \pm 76) \mathrm{MWm}^{-2} \mathrm{~K}^{-1}$. A similar change of the thermal interface conductance was previously reported by [37]. The difference between their results (red triangles in Figure 3a) and our data can be explained by differences in the interface itself, e.g., different levels of roughness, disorder or mixing. Regarding the thermal interface conductance between Pt and GaN of Sample C, it increased with temperature until reaching $623 \mathrm{~K}$, similar to the thermal conductance of the $\mathrm{Pt} / \mathrm{AlN}$ interface (Figure 3a-grey circles). Above that temperature, the thermal interface conductance showed a constant value of $\sim 3.8 \mathrm{~m}^{2} \mathrm{~K} / \mathrm{GW}$. This constant value is in agreement with the analysis published by Hopkins et al. [39]. There it was reported that above the Debye temperature of both materials at the interface (Pt: $240 \mathrm{~K}$ and GaN: $655 \mathrm{~K}$ ), the inelastic scattering became temperature-independent.
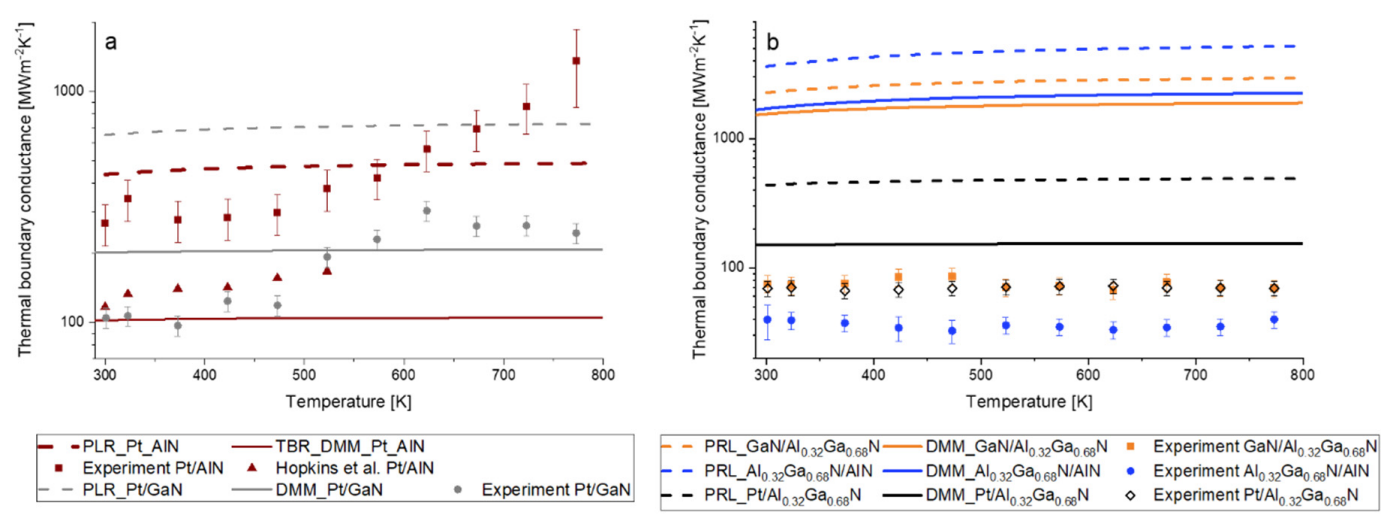

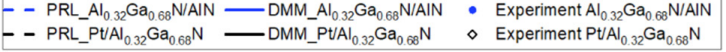

Figure 3. (a) Thermal boundary conductance across a Pt/AlN (red squares) and a Pt/GaN interface from $300 \mathrm{~K}$ to $773 \mathrm{~K}$; together with the results for Pt/AlN boundary conductance published by Hopkins et al. [37]. (b) Thermal boundary conductance across the $\mathrm{Al}_{0.32} \mathrm{Ga}_{0} \cdot{ }_{6} \mathrm{~N} / \mathrm{GaN}$ (orange squares), $\mathrm{Al}_{0.32} \mathrm{Ga}_{0} \cdot{ }_{68} \mathrm{~N} / \mathrm{AlN}$ (blue circles) and $\mathrm{Pt} / \mathrm{Al}_{0.32} \mathrm{Ga}_{0} \cdot{ }_{68} \mathrm{~N}$ (black rhombi). The calculated thermal conductance is shown as solid lines according to the phonon radiation limit (PRL) model and as dashed lines according to the diffuse mismatch model (DMM).

Concerning the thermal interface conductance across $\mathrm{Pt} / \mathrm{Al}_{0.32} \mathrm{Ga}_{0.68} \mathrm{~N}$ of Sample B (Figure $3 \mathrm{~b}$ ), it was an order of magnitude lower than that across $\mathrm{Pt} / \mathrm{AlN}$ of Sample A. It did not feature a significant change with temperature in the measured range ( $300 \mathrm{~K}-773 \mathrm{~K})$. Similar behaviour was obtained for the thermal interface conductance between $\mathrm{Al}_{0.32} \mathrm{Ga}_{0.68} \mathrm{~N} / \mathrm{AlN}$ and $\mathrm{GaN} / \mathrm{Al}_{0.32} \mathrm{Ga}_{0.68} \mathrm{~N}$ (Figure 3b), which were comparable to the results of a $\mathrm{GaSb} / \mathrm{GaAs}$ interface published in [40].

To visualise the relative contribution and the importance of the interface conductance in the HEMT layer stack, we visualised the normalized temperature profile from the $\mathrm{GaN}$ to the bottom of the AlN, for the system at $300 \mathrm{~K}$ and $773 \mathrm{~K}$ (Figure 4). The $\mathrm{Al}_{0.32} \mathrm{Ga}_{0.68} \mathrm{~N}$ showed the highest temperature gradient. However, the temperature jump at $\mathrm{Al}_{0.32} \mathrm{Ga}_{0.68} \mathrm{~N} / \mathrm{AlN}$ interface is two-third of the temperature decrease in the $\mathrm{Al}_{0.32} \mathrm{Ga}_{0.68} \mathrm{~N}$ layer and the $\mathrm{GaN} / \mathrm{Al}_{0.32} \mathrm{Ga}_{0.68} \mathrm{~N}$ one-third. It can also be seen that the temperature 
gradient in the GaN and AlN layer increases significantly from $300 \mathrm{~K}$ to $775 \mathrm{~K}$. Note that we did not visualise the leftmost layer since its interface conductance cannot be resolved.

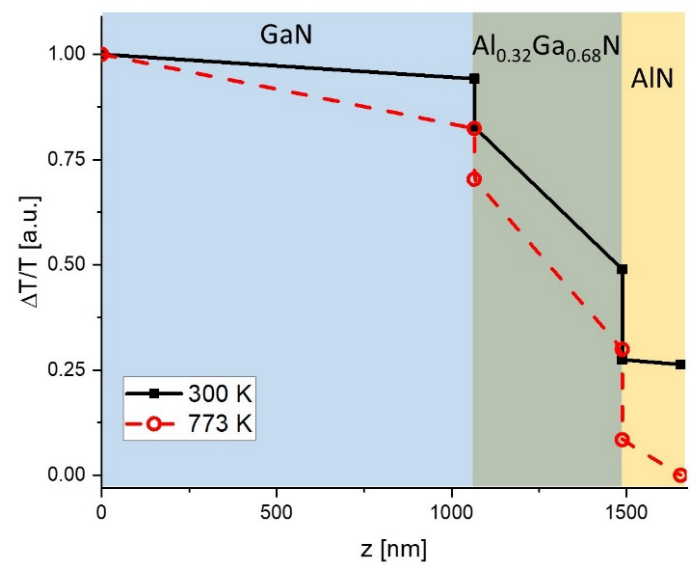

Figure 4. The normalized temperature profile of the HEMT structure: Starting with the GaN, which is underneath the heat source of the HEMT. The solid black line shows the temperature profile at $300 \mathrm{~K}$, while the dashed red line at $773 \mathrm{~K}$.

\section{Modelling Methodology and Discussion}

\subsection{Thermal Interface Conductance}

The thermal interface conductance from phonon scattering was modelled with the diffuse mismatch model (DMM-Equation (1)) [41] and the phonon radiation limit (PRL—Equation (2)) [42]. The DMM and the PRL models assume both elastic scattering of the phonons at the interface. Both models predict a constant thermal interface conductance in the high-temperature limit, at temperatures well above the Debye temperature. The DMM uses a transmission coefficient (a), which is a function of the phonon frequency $(\omega)$. a was computed from the group velocities and density of states (DOS) of both materials at the interface [42]. The behaviour in the high-temperature limit comes from the fact that in the DMM, the only temperature-dependent quantity is the phonon population on the hot side of the interface. In this model, the phonon population is given by the change of the Bose-Einstein distribution function with temperature $\left(\frac{\delta f(\omega, T)}{\delta T}\right)$ multiplied by the DOS of the material in the hot side $\left(D_{h o t, i}\right)$. Thus we obtain:

$$
h_{B D, D M M}=\frac{1}{4} \sum_{i} v_{h o t, i} \int_{0}^{\omega_{h o t, m a x}, i} a(\omega) \hbar \omega D_{h o t, i}(\omega) \frac{\delta f(\omega, T)}{\delta T} d \omega,
$$

where $\hbar$ is the Planck constant, $v_{h o t, i}$ is the phonon velocity of the acoustic phonon mode (i) in the hot side material and $\omega_{\text {hot,max }, i}$ the corresponding cut-off frequency.

For the PRL model, the transmission coefficient is assumed to be one, and a cut-off frequency is given by the highest frequency of the material on the hot side. Besides that, the only temperature-dependent quantity in the PRL model is $\frac{\delta f(\omega, T)}{\delta T}$ multiplied by the DOS of the material on the cold $\left(D_{\text {cold }, i}\right)$ side. This gives the equation:

$$
h_{B D, P R L}=\frac{1}{4} \sum_{i} v_{c o l d, i} \int_{0}^{\omega_{\text {hot }, \text { max }, i}} \hbar \omega D_{\text {cold }, i}(\omega) \frac{\delta f(\omega, T)}{\delta T} d \omega .
$$

The PRL always gives a higher value than the DMM, since it represents the upper limit of the elastic contribution to the thermal transport [43].

In the high-temperature limit: if the material on the hot side has a much lower Debye temperature than that on the cold side, the phonon population in the integrated frequency window (between zero and $\omega_{\text {hot,max }, i}$ ) does not change with temperature on both sides of the interface. Thus, 
the high-temperature limit of the interface conductance is always set by the material on the hot side, either by the DOS in the DMM or by introducing a cut-off in the PRL. If the Debye temperature of the material on the hot side is much higher than that of the cold side, the material from the hot side is still responsible for the temperature behaviour of the thermal interface conductance according to the DMM. In the PRL model, conversely, the material in the cold side is determining the temperature dependence of the thermal interface conductance.

The experimental thermal interface conductance of both Pt/AlN and $\mathrm{Pt} / \mathrm{GaN}$ increased both with temperature (see Figure 3a). Conversely, as the Debye temperature of $\mathrm{Pt}$ is $240 \mathrm{~K}$ [36], the values calculated from the DMM and PRL do not show a significant increase with temperature. Hopkins et al. [37] also reported an increasing $\mathrm{Pt} / \mathrm{GaN}$ interface conductance with temperature. They suggested that this temperature-dependent behaviour results from an inelastic phonon-scattering processes at the interface. This inelastic scattering affects the conductance, offering more channels for transport than the DMM and the PRL. In these models, the transmission coefficient is independent of temperature at high temperatures.

Concerning the thermal interface conductance involving AlGaN alloys (Figure 3b), both the DMM and PRL predicted a lower thermal interface conductance for the $P t / \mathrm{Al}_{0.32} \mathrm{Ga}_{0.68} \mathrm{~N}$ than for the $\mathrm{Al}_{0.32} \mathrm{Ga}_{0.68} \mathrm{~N} / \mathrm{AlN}$ and the $\mathrm{GaN} / \mathrm{Al}_{0.32} \mathrm{Ga}_{0.68} \mathrm{~N}$ interfaces. This is reasonable, as the $\mathrm{Pt} / \mathrm{Al}_{0.32} \mathrm{Ga}_{0.68} \mathrm{~N}$ has the highest mismatch in their sound velocities, which determines the transmission coefficient. For all interfaces, the PRL and the DMM overestimate the thermal interface conductance. These models, however, do not account for scattering mechanisms from defects at the interface, changes in the interatomic bonds near the interface or interfacial disorder (especially in well-matched materials) [44], that results in a reduction of the thermal conductance [43].

\subsection{Models for Phonon Scattering}

To provide insight into the thermal transport in a HEMT device, $\kappa$ of the constituent materials were also modelled by using analytical scattering models for phonons: Callaway [45], Holland [46] and Born-von-Karman (BvK) [47,48]. All analytical models have as a starting point the formula for the lattice thermal conductivity $(\kappa)$, having its origin in kinetic theory and being derived from the Peierls-Boltzmann transport equation. $\kappa$ can be expressed as a function of the phonon frequency $(\omega)$ and the temperature $(T)$, including the summation over the phonon modes $(i)$ :

$$
\kappa=\frac{1}{3} \sum_{i} \int C(\omega, T) v_{g}^{2}(\omega) \tau_{e f f}(\omega, T) d \omega,
$$

where $C$ is the volumetric specific heat capacity, $v_{g}$ is the phonon group velocity and $\tau_{e f f}$ is the total relaxation time. $\tau_{\text {eff }}$ depends on the phonon scattering mechanisms. $v_{g}=\delta \omega / \delta k$ and $C(\omega, T)=$ $\hbar \omega D(\omega)\left(\frac{\delta f_{B E}}{\delta T}\right)=\left(\frac{\hbar \omega}{T}\right)^{2} D(\omega) e^{\frac{\hbar \omega}{k_{B} T}} /\left(k_{B}\left(e^{\frac{\hbar \omega}{k_{B} T}}-1\right)^{2}\right)$ are determined by the phonon dispersion relation. Here, $k$ is the wavenumber, $\hbar$ is the Planck constant, $k_{B}$ the Boltzmann constant, $D(\omega)$ the phonon DOS and $f_{B E}$ is the Bose-Einstein distribution.

The Callaway model is based on a linear dispersion relation (Debye model), while the BvK model uses a sine-type dispersion, capturing the increased DOS near the Brillouin zone edge. Details about the analytical models used are given in Appendix A. The models only consider heat transport by acoustic phonons (i.e., the heat transport by optical phonons were neglected).

Following Matthiessens's rule, $\tau_{\text {eff }}$ can be expressed in terms of the relaxation times of different scattering processes as:

$$
\tau_{e f f}^{-1}=\tau_{U}^{-1}+\tau_{P D}^{-1}+\tau_{B}^{-1}
$$


$\tau_{U}, \tau_{P D}, \tau_{B}$ are associated with Umklapp scattering [49], point-defect scattering [50], and the boundary scattering [51], respectively. These relaxation times have different dependencies on temperature and frequency [52].

$$
\begin{gathered}
\tau_{U}^{-1}(\omega, T)=\frac{2 k_{B} \delta \gamma^{2}}{\left(6 \pi^{2}\right)^{1 / 3} M v_{p}^{2} v_{g}} \omega^{2} T e^{-\frac{\theta}{b T}} \\
\tau_{P D}^{-1}(\omega, T)=\frac{\delta^{3}}{4 \pi v_{p}^{2} v_{g}} \omega^{4} \Gamma \\
\tau_{B}^{-1}=\frac{v_{g}}{\alpha L}
\end{gathered}
$$

Here, $\gamma$ denotes the Grüneisen parameter and $\delta$ the characteristic length scale of the lattice (i.e., cubic root of the atomic volume). The atomic volume was calculated by dividing the atomic molar mass $\left(M_{M o l}\right)$ by the density. $M$ is the average mass of an atom in the crystal $\left(M_{M o l}\right.$ divided by the number of atoms in the unit cell). $b$ is a constant characteristic of the vibrational spectrum of the material, $\alpha$ is a specularity factor, $v_{P}$ is the phonon phase velocity and $L$ is the characteristic size of the material. In the case of the Debye model, $v_{g}$ and $v_{p}$ were both approximated as the speed of sound $v_{s}$.

In Equation (6), $\Gamma$ denotes the phonon-scattering parameter. For a single element, $\Gamma$ describes the scattering by point defects $\left(\Gamma=\Gamma_{i m p}\right)$, which is influenced by the doping density and the growth method [14]. For alloys, the scattering parameter also includes the scattering caused by alloying $\left(\Gamma_{\text {alloy }}\right)$, $\Gamma=\Gamma_{\text {imp }}+\Gamma_{\text {alloy }}$ [33]. $\Gamma_{\text {alloy }}$ is related to the difference in mass and strain-field (the lattice constants) between two constituents of an alloy [53].

The material parameters used in our calculations are summarized in Table $1 ; \gamma, v, \mathrm{n}$ and $\rho$ were obtained from ab-initio calculations, using ThermElpy [54] and Vienna Ab-initio Simulation Package (VASP) [55]. Here, $\gamma$ is the high-temperature limit of the Grüneisen parameter, obtained by fitting Birch-Murnaghan equation of states and extracting the pressure derivative of the bulk modulus. For the $\mathrm{AlGaN}$ alloys, these values were extracted from an $\mathrm{Al}_{0.5} \mathrm{Ga}_{0.5} \mathrm{~N}$ alloy. The values $M$ and $\rho$ of the alloys were calculated by the relation $\sum_{i} f_{i} \times z$, where $f_{i}$ is the mass fraction of the component and $\mathrm{z}$ stands for the parameter either $M$ or $\rho$.

Table 1. Material parameters used for the theoretical models of the lattice thermal conductivity.

\begin{tabular}{cccccccc}
\hline Materials & $\gamma$ & $v_{L}[\mathrm{~m} / \mathbf{s}]$ & $v_{T 1}[\mathrm{~m} / \mathbf{s}]$ & $v_{T 2}[\mathrm{~m} / \mathbf{s}]$ & $\mathbf{n}\left[\AA^{-3}\right]$ & $\mathbf{M}[\mathrm{kg}]$ & $\rho\left[\mathrm{kg} / \mathbf{m}^{3}\right]$ \\
\hline $\mathrm{AlN}$ & 1.77 & 10,751 & 6027 & 6406 & 0.0941 & $3.48 \times 10^{-26}$ & 3201 \\
$\mathrm{GaN}$ & 2.05 & 7538 & 4022 & 4566 & 0.0852 & $6.95 \times 10^{-26}$ & 5923 \\
$\mathrm{Al}_{0.32} \mathrm{Ga}_{0.68} \mathrm{~N}$ & 1.91 & 8962 & 4783 & 5322 & 0.0916 & $5.82 \times 10^{-26}$ & 5136 \\
$\mathrm{Al}_{0.17} \mathrm{Ga}_{0.83} \mathrm{~N}$ & 1.91 & 8962 & 4783 & 5322 & 0.0916 & $6.35 \times 10^{-26}$ & 5510 \\
\hline
\end{tabular}

$\gamma$ Grüneisen parameter; $v_{L}$ longitudinal acoustic phonon velocities; $v_{T}$ transverse acoustic phonon velocities; $\mathrm{n}$ number of atoms per volume in the unit cell; $\mathrm{M}$ average mass of an atom in the crystal; $\rho$ density.

The determination of the thermal conductivity trend was limited by the temperature-dependence of the aforementioned scattering mechanisms. For the three models considered (Equations (5)-(7)), $b, \Gamma$ and $\alpha$ were determined by fitting the modelled thermal conductivity to the experimental one (Figure 2). The values of the fitting parameters are listed in Table 2.

Table 2. Fitting parameters of several phonon scattering mechanisms used in the three models.

\begin{tabular}{cccccccccc}
\hline \multirow{2}{*}{ Materials } & \multicolumn{3}{c}{ Callaway } & \multicolumn{3}{c}{ Holland } & \multicolumn{3}{c}{ BvK } \\
\cline { 2 - 10 } & $\boldsymbol{b}$ & $\boldsymbol{\Gamma}$ & $\boldsymbol{\alpha}$ & $\boldsymbol{b}$ & $\boldsymbol{\Gamma}$ & $\boldsymbol{\alpha}$ & $\boldsymbol{b}$ & $\boldsymbol{\Gamma}$ & $\boldsymbol{\alpha}$ \\
\hline $\mathrm{AlN}$ & 3 & $3 \times 10^{-4}$ & 0.3 & 3 & 0.0021 & 0.87 & 3 & $8 \times 10^{-5}$ & 0.3 \\
$\mathrm{GaN}$ & 3 & $2 \times 10^{-4}$ & 1 & 1.6 & 0.0026 & 0.29 & 0.85 & $9 \times 10^{-5}$ & 1 \\
$\mathrm{Al}_{0.32} \mathrm{Ga}_{0.68} \mathrm{~N}$ & 3 & 0.056 & 1 & 3 & 0.0988 & 0.19 & 3 & 0.4 & 1 \\
$\mathrm{Al}_{0.17} \mathrm{Ga}_{0.83} \mathrm{~N}$ & 3 & 0.030 & 0.85 & 3 & 0.0854 & 0.11 & 3 & 0.2 & 0.96 \\
\hline
\end{tabular}


The frequency dependence of the different scattering mechanisms (Equations (5)-(7)) is shown in Figure 5. As can be seen in Equations (5)-(7) only $\tau_{U}$ features a temperature dependence. To show the effect of temperature on $\tau_{U}$ and hence $\tau_{\text {eff }}$, these values were plotted at $300 \mathrm{~K}$ and at $773 \mathrm{~K}$ (see Figure 5 : solid vs. dashed lines). In all models $\tau_{B}$ dominates the phonon scattering at low $\omega$ (e.g., $<3 \mathrm{THz}$ at $773 \mathrm{~K}$ in the $\mathrm{BvK}$ model). At higher frequencies and high temperature $(773 \mathrm{~K}) \tau_{U}$ dictates the heat transport. For frequencies $>10 \mathrm{THz}, \tau_{P D}$ is the main scattering mechanism for $\mathrm{Al}_{0.32} \mathrm{Ga}_{0.68} \mathrm{~N}$ (Figure $5 b, f)$ in contrast to GaN (Figure 5a,e). This behaviour of the relaxation times explains why the thermal conductivity of $\mathrm{Al}_{0.32} \mathrm{Ga}_{0.68} \mathrm{~N}$ is less affected by temperature. In contrast to the Callaway and Holland models, which use the Debye dispersion, the BvK model shows a frequency-dependent $\tau_{B}$. In the BvK model, $\tau_{B}$ increases with frequency and $\tau_{U}$ dominates at low frequencies in $\mathrm{GaN}$ and in $\mathrm{Al}_{0.32} \mathrm{Ga}_{0.68} \mathrm{~N}$ at $773 \mathrm{~K}$. The Holland model offers insight into the scattering mechanisms of each phonon branch (Figure $5 \mathrm{c}, \mathrm{d}$ ). The two transverse phonon branches dominate the low-frequency range while the longitudinal phonon branch becomes dominant at higher frequencies $(>5 \mathrm{THz})$.
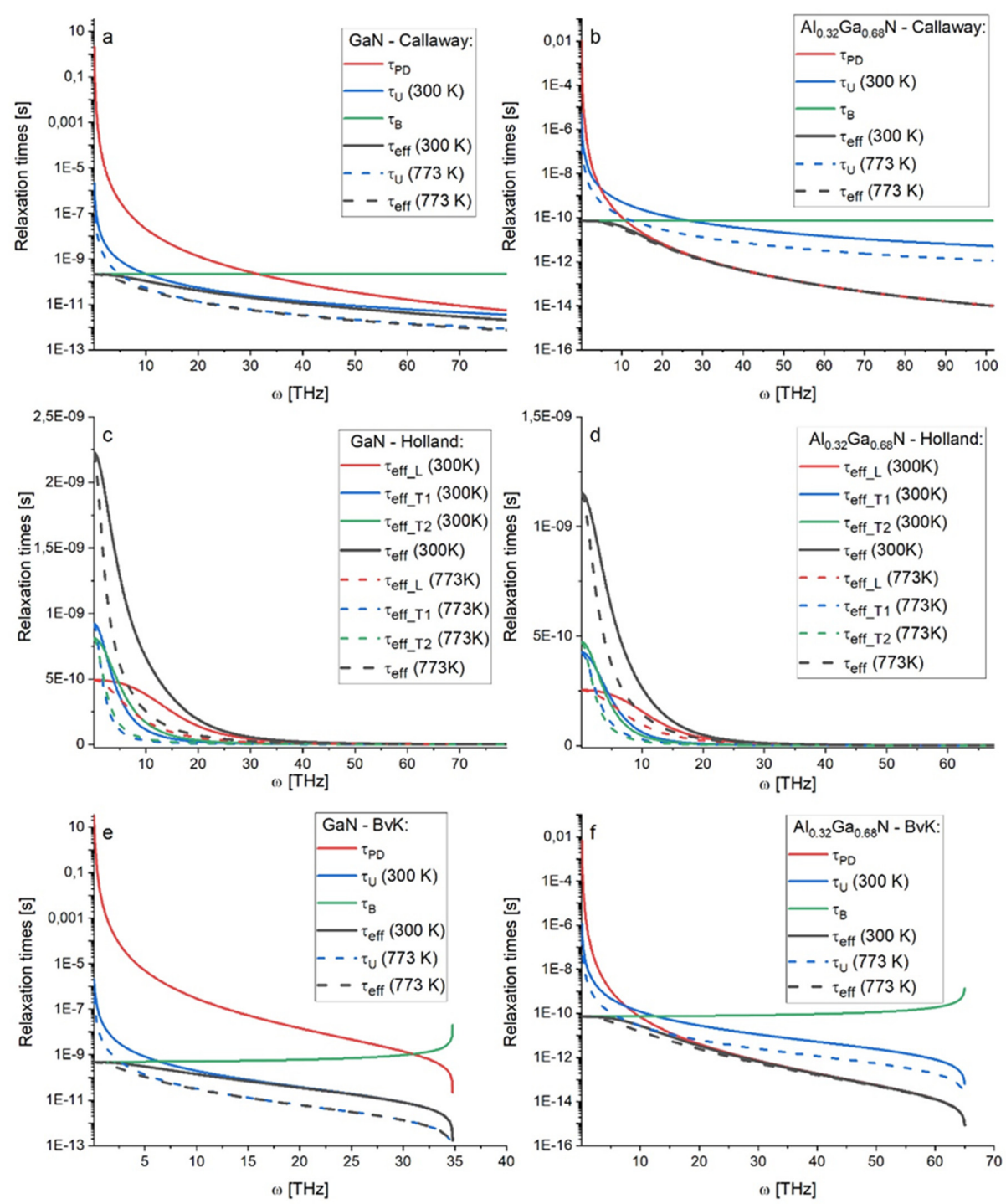

Figure 5. $(\mathbf{a}, \mathbf{b})$ Frequency dependence of the three different scattering mechanisms according to the Callaway model; (c,d) frequency dependence of the relaxation times for the longitudinal and two transverse phonon branches according to the Holland model; $(\mathbf{e}, \mathbf{f})$ frequency dependence of the three different scattering mechanisms of the BvK model. The left-hand side figures $(\mathbf{a}, \mathbf{c}, \mathbf{e})$ are the relaxation times for $\mathrm{GaN}$, and the right-hand side figures are the relaxation times for $\mathrm{Al}_{0.32} \mathrm{Ga}_{0.68} \mathrm{~N}$. 


\subsection{Models for the Size Effect in Cross-Plane Thermal Transport}

We have tested three different approaches to predict the size effect on cross-plane transport given by layer thickness variations:

1. A suppression function-based approach as proposed by Hua and Minnich [19].

2. A model using simply the boundary scattering law as given in Equation (3) [56]. In the following it is referred to as the "simple model".

3. A model derived from the phonon hydrodynamic equations by Guo and Wang [21].

In our work, all three models were compared to the BvK model. In the first approach, we used the thickness-dependent thermal conductivity according to the Hua and Minnich suppression function approach [19], that uses a model analogous to the Fuchs-Sondheimer [57] expression for the thermal conductivity. Accordingly, the calculation of the thickness-dependent thermal conductivity can be written as:

$$
\kappa(L)=\int_{0}^{\omega_{\max }} \frac{1}{3} C(\omega) v_{g} \Lambda(\omega) \mathrm{S}(\operatorname{Kn}(\omega), L) d \omega,
$$

where $\Lambda(\omega)$ is the bulk phonon mean free path and $\mathrm{Kn}$ is the Knudsen number. $S(\operatorname{Kn}(\omega), L)=$ $1+3 \mathrm{Kn}(\omega) \cdot\left(E_{5}\left(\mathrm{Kn}^{-1}(\omega)\right)-0.25\right)$ is a layer thickness $(L)$ dependent suppression function. $\Lambda(\omega)=$ $v_{g} \tau_{e f f_{\text {mat }}}(\omega)$ was calculated by using the aforementioned fitted models. $\tau_{\text {eff mat }}$ is similar to $\tau_{e f f}$ in Equation (4) without $\tau_{B}$. By using the fit parameters in Table 2, $\tau_{\text {eff }}$ mat of all three transport models ((Callaway, Holland and BvK)) was calculated and used in Equation (8). Figure 6 shows the thickness-dependent thermal conductivity for the four materials at $300 \mathrm{~K}$. The Holland model for AlN and $\mathrm{GaN}$ predicted lower thermal conductivities at a small thickness $\left(<10^{-4} \mathrm{~m}\right)$ compared with the other models. The size-dependence extracted from the Holland model did not agree well with the experimental values; it predicts thermal conductivity for AlN and GaN that is too low. The thermal conductivity of AlN and GaN showed strong thickness dependence. The BvK model showed the highest bulk thermal conductivity while the Callaway model the smallest. E.g., The $167 \mathrm{~nm}$ thick AlN showed a reduction by $41 \%$ for the Callaway model and $36 \%$ for the BvK model compared the corresponding bulk value. The $\kappa(L)$ of $\mathrm{GaN}$ at $1065 \mathrm{~nm}$ resulted in $78 \%$ of the corresponding bulk value for the Callaway model and $52 \%$ for the BvK model, which was also reported by [58]. The values predicted by the BvK model of $\kappa(L)$ for GaN (green dashed-dotted line Figure $6 \mathrm{~b}$ ) were in agreement with the results reported in [59]. Comparing the three transport models for the alloys, there was a difference of $10 \%$ for $\mathrm{Al}_{0.32} \mathrm{Ga}_{0.68} \mathrm{~N}$ and $18 \%$ for $\mathrm{Al}_{0.17} \mathrm{Ga}_{0.83} \mathrm{~N}$ in their size-dependencies. For example, the thermal conductivity of the $65 \mathrm{~nm}$ thick $\mathrm{Al}_{0.17} \mathrm{Ga}_{0.83} \mathrm{~N}$ showed $9 \%$ of the bulk thermal conductivity in the BvK model (Figure 6d).

The second approach used to compute the size effect on the cross-plane thermal conductivity takes into account boundary scattering by using the thickness-dependent boundary relaxation time (Equation (7)) to calculate the total relaxation time. The thermal conductivity is computed according to Equation (3) [56]. The results of this model are shown as dashed lines in Figure 7.

The third approach to calculate size effects uses the formula derived from Guo and Wang [21]:

$$
\frac{\kappa(L, \omega)}{\kappa_{\text {bulk }}(\omega)}=\left(1+\frac{(1+s)}{(1-s)} \frac{4}{3} \mathrm{Kn}_{L}(\omega)\right)^{-1}
$$

where $\kappa_{\text {bulk }}(\omega)$ is the spectral thermal conductivity as given in Equation (3), without integrating over $\omega$. The Knudsen number is given as $\operatorname{Kn}_{L}(\omega)=\Lambda(\omega) / L$, where $\Lambda(\omega)$ is the mean free path spectrum. The term $(1+s) /(1-s)$ accounts for the specularity factor $1 / \alpha$ (see Table 2). For instance, for perfectly diffuse boundary scattering $s=0$ and $\alpha=1$. For boundaries with specular scattering contribution $s>0$, approaching 1 for fully specular reflection and $\alpha<1$, approaching 0 , respectively. Thus, the effective thermal conductivity becomes smaller with increasing specular scattering at the boundary for the cross-plane case. Note, this is the opposite of the in-plane case. A detailed discussion of the cross-plane 
and in-plane effective thermal conductivity is given by Guo and Wang [21]. The effective cross-plane thermal conductivity was calculated by integrating over $\omega$, analogous to Equation (8), by inserting Equation (9) instead of $S(\mathrm{Kn}(\omega), L)$ (see dotted lines in Figure 7).
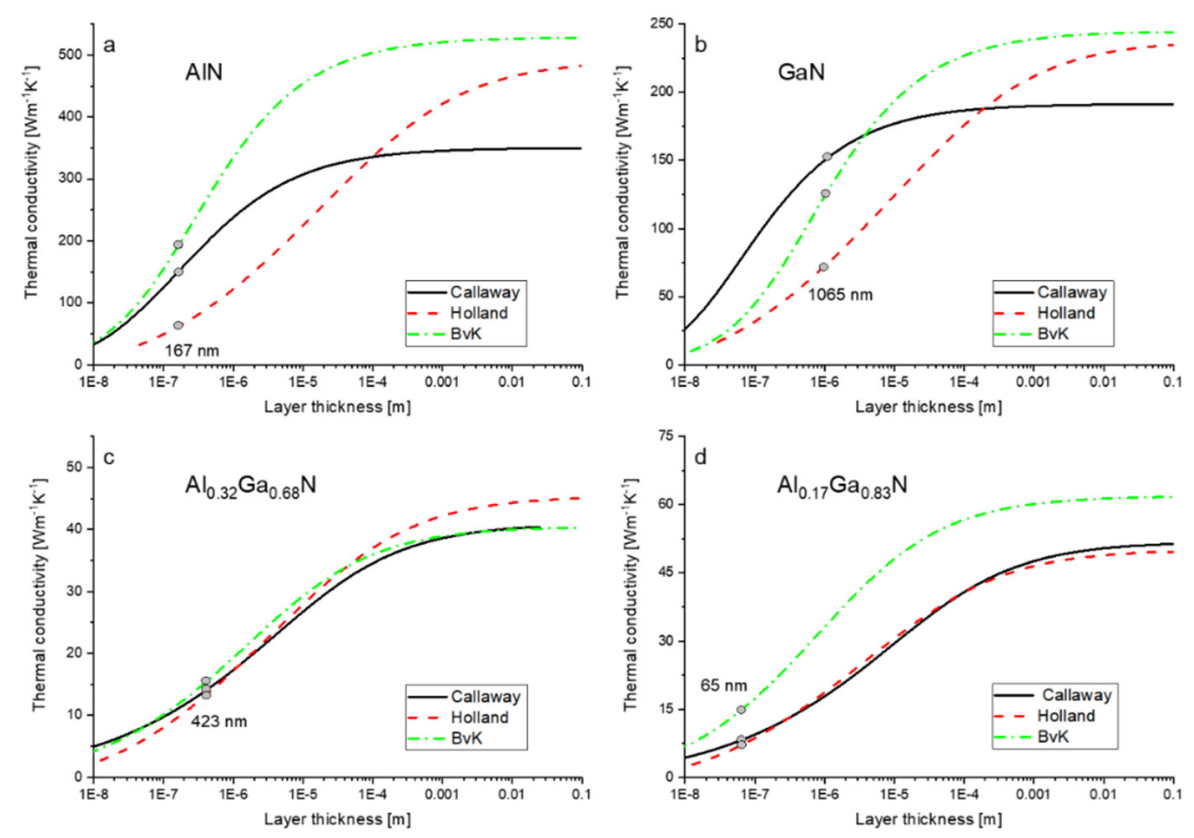

Figure 6. Thickness dependent thermal conductivity as calculated using the Hua-Minnich suppression function approach for (a) $\mathrm{AlN}$, (b) $\mathrm{Al}_{0.32} \mathrm{Ga}_{0.68} \mathrm{~N}$, (c) $\mathrm{GaN}$, and (d) $\mathrm{Al}_{0.17} \mathrm{Ga}_{0.83} \mathrm{~N}$. Calculations were performed at $300 \mathrm{~K}$ determined by using Equation (8) with the relaxation times determined by the Callaway, Holland and BvK models.

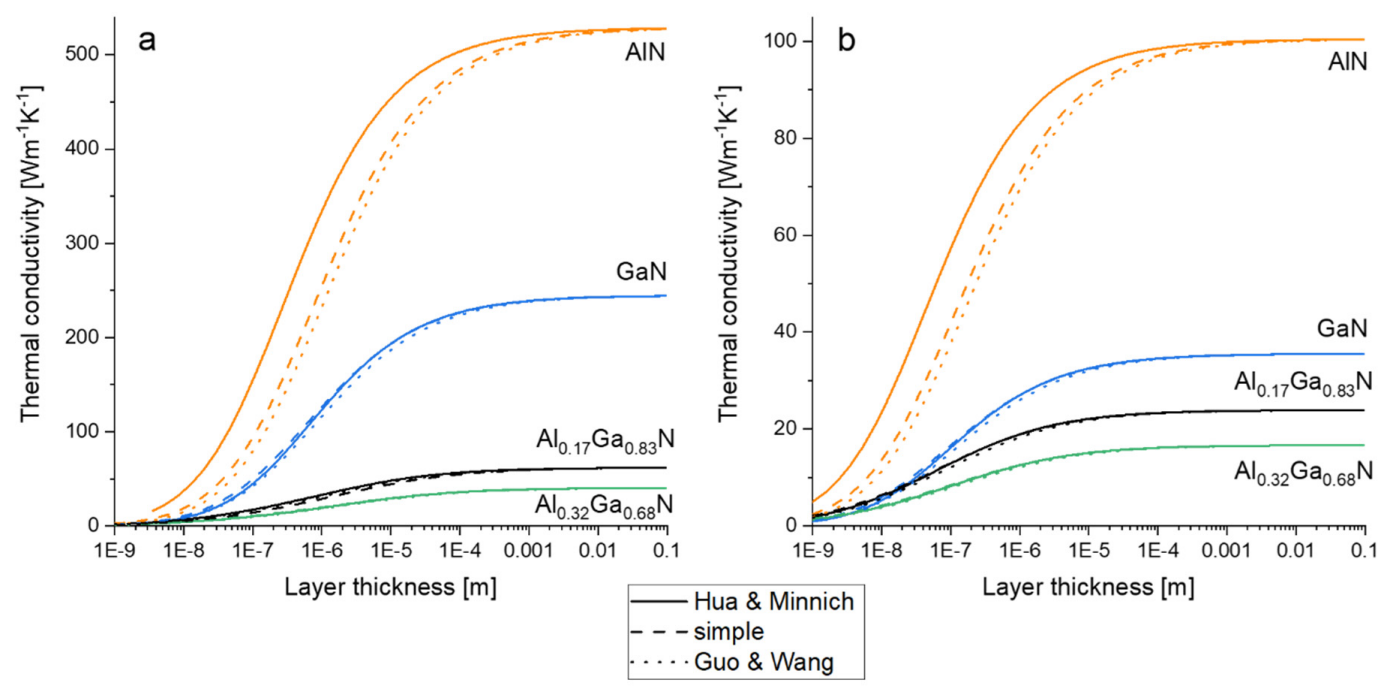

Figure 7. The size-dependent thermal conductivity for $\mathrm{AlN}$ (orange), $\mathrm{GaN}$ (blue), $\mathrm{Al}_{0.32} \mathrm{Ga}_{0.68} \mathrm{~N}$ (green) and $\mathrm{Al}_{0.17} \mathrm{Ga}_{0.83} \mathrm{~N}$ (black) at (a) $300 \mathrm{~K}$ and (b) $773 \mathrm{~K}$. The size-dependent thermal conductivity evaluated within the framework of the BvK transport model. The Hua-Minnich approach is drawn as solid lines, the simple boundary scattering approach as dashed lines, and the approach of Guo and Wang as dotted lines. 
Figure 7 shows the size-dependent thermal conductivity of the three models at (a) $300 \mathrm{~K}$ and (b) $773 \mathrm{~K}$. Comparing the size effect at $300 \mathrm{~K}$ and $773 \mathrm{~K}$, the convergence to the bulk thermal conductivity (e.g., $90 \%$ of $\kappa_{G a N}(L=\infty)$ ) happens at smaller thicknesses at $773 \mathrm{~K}$. At higher temperatures, the phonon-phonon scattering increases, and hence the mean free path of the phonons contributing to the thermal conductivity is shorter for $773 \mathrm{~K}$ than for $300 \mathrm{~K}$.

All three models for predicting the size effect agree very well when the specularity parameter $\alpha$ is close to one or equal to one (see Table 2). In the AlN, where $\alpha$ is 0.3 , the simple model and the model of Gua and Wang showed similar results. For AlN, both models predict a lower thermal conductivity than the Hua and Minnich model for layer thicknesses $<0.001 \mathrm{~m}$, the convergence of $\kappa(L)$ is also broader.

\section{Conclusions}

The constituent materials of an AlGaN-GaN-based HEMT, and the interfaces between them were investigated by a TDTR measurement setup. The measured thermal interface conductance was compared to the values calculated in the framework of the DMM and the PRL models. In contrast to the elastic DMM and PRL models, the measured interface conductance showed a stronger increase with temperature. This observation suggests a contribution of inelastic scattering processes. The $\mathrm{Pt} / \mathrm{AlN}$ thermal interface conductance increased with temperature from $(269 \pm 54) \mathrm{MW} / \mathrm{m}^{2} \mathrm{~K}$ at $300 \mathrm{~K}$ to $(1358 \pm 503) \mathrm{MW} / \mathrm{m}^{2} \mathrm{~K}$ at $773 \mathrm{~K}$. The $\mathrm{Pt} / \mathrm{GaN}$ thermal interface conductance increased from $(105 \pm 11)$ $\mathrm{MW} / \mathrm{m}^{2} \mathrm{~K}$ at $300 \mathrm{~K}$ until reaching a plateau of $3 \cdot 10^{8} \mathrm{~W} / \mathrm{m}^{2} \mathrm{KW}$ at $600 \mathrm{~K}$. The thermal interface conductance with $\mathrm{Al}_{0.32} \mathrm{Ga}_{0.68} \mathrm{~N}$ showed no significant temperature-dependence.

The thermal conductivities of the $(167 \pm 7) \mathrm{nm}$ AlN and $(1065 \pm 7) \mathrm{nm} \mathrm{GaN}$ at $300 \mathrm{~K}\left(\kappa_{\text {AlN }}=(130 \pm 38)\right.$ $\mathrm{Wm}^{-1} \mathrm{~K}^{-1}$ and $\left.\kappa_{G a N}=(220 \pm 38) \mathrm{Wm}^{-1} \mathrm{~K}^{-1}\right)$ were found to be an order of magnitude higher than that of the alloy. The $\kappa$ of $(423 \pm 5) \mathrm{nm} \mathrm{Al}_{0.32} \mathrm{Ga}_{0.68} \mathrm{~N}$ layer was found to be $(11.2 \pm 0.7) \mathrm{Wm}^{-1} \mathrm{~K}^{-1}$ and that of the of $(65 \pm 5) \mathrm{nm} \mathrm{Al}_{0.17} \mathrm{Ga}_{0.83} \mathrm{~N}$ layer was $(9.7 \pm 0.6) \mathrm{Wm}^{-1} \mathrm{~K}^{-1}$. As expected, their thermal conductivities decreased with increasing temperature in the range of 300 to $773 \mathrm{~K}$. From the analysis of the relaxation times, it has been shown that besides boundary scattering, the Umklapp scattering was dominant for the thermal conductivity in pure AlN and pure GaN. Point-defect scattering, conversely, dictated the thermal conductivity of the alloys.

The investigated material layers with nanometer to micrometre thicknesses generally showed a reduced thermal conductivity relative to the bulk. The size effect for the cross-plane phonon transport was calculated by using three different models: the suppression function-based approach, the approach taking into account the boundary scattering, and the approach based on phonon hydrodynamic equations. The last two models include specular phonon scattering effects at the boundary. In contrast, the suppression function-based approach assumes perfectly diffusive scattering. To apply this for the AlGaN-GaN-based HEMT layer stack can be content of future work. We observed an agreement between the three boundary models, in the prediction of size-dependent cross-plane thermal conductivity (see Figure 7). The uncertainty, which is introduced by the transport model (Callaway, Holland, BvK) was much higher than for the boundary model (compare Figures 6 and 7).

The categorical low thermal conductivity of the AlGaN layers in the HEMT structure hinders the heat dissipation from the junction to the substrate and can lead to hot spots. This increases the importance of the GaN-layer as a heat spreader for efficient heat transport from the junction to the substrate. Our work highlights the role of interfaces and size effects; these features lessen the thermal conductance in HEMTs. It also designates that a significant contribution of the phonons that transport heat in GaN have long MFPs in the range of the involved layer thicknesses. This fact should be considered for a better exploitation of the intrinsic thermal conductivity of the materials used in microelectronic devices as HEMTs. Overall, the reported thermal transport results can be used to evaluate self-heating effects in AlGaN-GaN HEMT heterostructure and might serve as a guide for advanced optimization, taking thermal considerations into account. 
Author Contributions: Conceptualization, L.M. and R.H.; methodology, L.M.; ab intio calculations, T.D.; formal analysis, R.H. and J.S.; investigation, L.M.; writing-original draft preparation, L.M.; writing-review and editing R.H. and J.S.; project administration, J.S.; All authors have read and agreed to the published version of the manuscript.

Funding: The authors gratefully acknowledge the financial support under the scope of the COMET program within the K2 Center "Integrated Computational Material, Process and Product Engineering (IC-MPPE)" (Project No 859480). This program is supported by the Austrian Federal Ministries for Climate Action, Environment, Energy, Mobility, Innovation and Technology (BMK) and for Digital and Economic Affairs (BMDW), represented by the Austrian research funding association (FFG), and the federal states of Styria, Upper Austria and Tyrol.

Acknowledgments: The authors would like to thank Natalia Bedoya-Martínez for her help.

Conflicts of Interest: The authors declare no conflict of interest.

\section{Appendix A}

In the following section, three different analytical phonon transport models are summarized in a detailed way: the Callaway, Holland and BvK models. The models were used to provide insight into the temperature-dependent thermal conductivity. The Callaway model is based on the Debye model that uses a dispersion relation for a single, degenerated phonon branch [45]. The Debye model approximates the dispersion relation as linear, and hence the frequency-dependent phonon group velocity as constant value:

$$
\omega=v_{s} q
$$

where $q$ is the phonon wave vector and $v_{s}$ is the sound velocity. Here, the $v_{g}$ and $v_{p}$ are assumed to be $v_{s}$. For $v_{S}$ the average value over all acoustic phonon branches (longitudinal $\left(v_{L}\right)$ and the two transverse $\left.\left(v_{T}\right)\right), v_{S}=3 /\left(v_{L}^{-1}+v_{T 1}^{-1}+v_{T 2}^{-1}\right)$ is taken. Note, this simplification, due to the Debye dispersion, causes an overestimation of the group velocity especially of high-frequency phonons in the Debye model $D(\omega)=\frac{3 \omega^{2}}{2 \pi^{2} v_{s}^{3}}$. Substituting $\omega$ with $x=\frac{\hbar \omega}{k_{B} T}, C(x)$ can be written as:

$$
C(x)=\frac{3 k_{B}^{3} T^{2}}{2 \pi^{2} \hbar^{2} v_{s}^{3}} \frac{x^{4} e^{x}}{\left(e^{x}-1\right)^{2}}
$$

Here, $\hbar$ denotes the Plank constant, and $k_{B}$ the Boltzmann constant. By inserting $C(x)$ in Equation (3), the lattice thermal conductivity can be calculated with the following equation:

$$
\kappa_{\text {Callaway }}=\frac{\kappa_{B}^{4} T^{3}}{2 \pi^{2} \hbar^{3} v_{s}}\left(\int_{0}^{\frac{\theta_{D}}{T}} \tau_{c} \frac{x^{4} e^{x}}{e^{x}-1} d x+\frac{\int_{0}^{\frac{\theta_{D}}{T}} \frac{\tau_{c}}{\tau_{N}} \frac{x^{4} e^{x}}{\left(e^{x}-1\right)^{2}} d x}{\int_{0}^{\frac{\theta_{D}, p o l}{T}} \frac{\tau_{c}}{\tau_{N} \tau_{R}} \frac{x^{4} e^{x}}{\left(e^{x}-1\right)^{2}} d x}\right)
$$

For this model $\tau_{e f f}$ is the combined scattering relaxation time $\left(\tau_{C}\right)$, where $\tau_{C}^{-1}=\tau_{N}^{-1}+\tau_{R}^{-1}$ and $\tau_{R}^{-1}=\tau_{U}^{-1}+\tau_{P D}^{-1}+\tau_{B}^{-1}$. By assuming $\tau_{N} \gg \tau_{R}, \tau_{R} \approx \tau_{C}$ and Equation (A3) reduces to (A4).

$$
\kappa_{\text {Callaway }}=\frac{k_{B}^{4} T^{3}}{2 \pi^{2} \hbar^{3} v_{\mathcal{S}}} \int_{0}^{\theta_{D} / T} \tau_{\mathcal{c}}(x) \frac{x^{4} e^{x}}{\left(e^{x}-1\right)^{2}} d x
$$

where $\theta_{D}$ is the Debye temperature of the material under investigation. The Debye temperature was calculated according to $\theta_{D}=\frac{\hbar}{k_{B}}\left(6 \pi^{2} n\right)^{1 / 3} v_{s}$, where n number of atoms per volume in the unit cell.

The second model is the Holland model, which is also based on the Debye model, but taking into account the two types of polarization. The calculation of the thermal conductivity is separated into the contributions of the longitudinal $\left(\kappa_{L}\right)$ and the two transverse $\left(\kappa_{T}\right)$ phonon branches. The thermal conductivity $\left(\kappa_{i}\right)$ of each phonon mode is based on the Equation (A4). For each polarization the 
dispersion relation is assumed to be linear, so each phonon branch has its phonon velocity of $v_{L}, v_{T 1}$ and $v_{T 2}$.

$$
\kappa_{\text {Holland }}=\kappa_{L}+\kappa_{T 1}+\kappa_{T 2}=\sum_{i} \kappa_{i} .
$$

The third model is the BvK model, where the dispersion relation is:

$$
\omega=\omega_{\max } \sin \left(\frac{\pi q}{2 q_{\max }}\right)
$$

Here, the cut-off wave vector $q_{\max }=\omega_{D} / v_{S}$ and the cut-off frequency $\omega_{\max }=2 \omega_{D} / \pi$ are the same as in the Debye model using $\omega_{D}=\theta_{D} k_{B} / \hbar=\left(6 \pi^{2} n\right)^{1 / 3} v_{s}$. Hence, the phonon group velocity $v(\omega)$ is the same as is used for the models as mentioned above based on the Debye model at low $\omega$. The corresponding temperature can be expressed as $\theta_{\max }=\hbar \omega_{\max } / k_{B}$. However, the more realistic dispersion reduces the $v(\omega)$ for high-frequency phonons. The phonon DOS is $D(\omega)=\frac{3}{2 \pi^{2}} \frac{\omega^{2}}{v_{g} v_{p}^{2}}$, where $v_{g}\left(v_{g}=d \omega / d q\right)$ is the phonon group velocity and $v_{P}\left(v_{P}=\Delta \omega / \Delta q\right)$ is the phonon phase velocity. In the BvK dispersion $v_{g}=v_{s} \sqrt{1-\left(\omega / \omega_{\max }\right)^{2}}=v_{s} \sqrt{1-\left(T x / \theta_{\max }\right)^{2}}$ and $v_{P}=\frac{\omega}{\frac{2}{\pi} q_{\max } \sin ^{-1}\left(\omega / \omega_{\max }\right)}=$ $\frac{x}{\frac{2}{\pi} q_{\max } \sin ^{-1}\left(T x / \theta_{\max }\right)} \frac{k_{B} T}{\hbar}, v_{S}$ is the average value over all acoustic phonon branches. The spectral heat capacity can be written as:

$$
C(\omega)=\frac{6 \hbar^{2} q_{\max }^{2}}{\pi^{4} k_{B} T^{2} v_{s}} \frac{\omega^{2} e^{\frac{\hbar \omega}{k_{B} T}}\left(\sin ^{-1}\left(\omega / \omega_{\max }\right)\right)^{2}}{\left(e^{\frac{\hbar \omega}{k_{B} T}}-1\right)^{2} \sqrt{1-\left(\omega / \omega_{\max }\right)^{2}}}
$$

and

$$
C(x)=\frac{6 q_{\max }^{2} k_{B}}{\pi^{4} v_{s}} \frac{x^{2} e^{x}\left(\sin ^{-1}\left(T x / \theta_{\max }\right)\right)^{2}}{\left(e^{x}-1\right)^{2} \sqrt{1-\left(T x / \theta_{\max }\right)^{2}}}
$$

The thermal conductivity can be calculated as:

$$
\kappa_{B v K}=\int_{0}^{\frac{\theta_{\max }}{T}}\left(\frac{k_{B} T}{\hbar}\right) C(x) v_{g}^{2}(x) \tau_{C}(x) d x .
$$

\section{References}

1. Baskaran, S.; Mohanbabu, A.; Anbuselvan, N.; Mohankumar, N.; Godwinraj, D.; Sarkar, C.K. Modeling of 2DEG sheet carrier density and DC characteristics in spacer based AlGaN/AIN/GaN HEMT devices. Superlattices Microstruct. 2013, 64, 470-482. [CrossRef]

2. Mishra, U.K.; Shen, L.; Kazior, T.E.; Wu, Y.-F. GaN-based RF power devices and amplifiers. Proc. IEEE 2008, 96, 287-305. [CrossRef]

3. Fitch, R.C.; Walker, D.E.; Green, A.J.; Tetlak, S.E.; Gillespie, J.K.; Gilbert, R.D.; Sutherlin, K.A.; Gouty, W.D.; Theimer, J.P.; Via, G.D.; et al. Implementation of high-power-density X-band AlGaN/GaN high electron mobility transistors in a millimeter-wave monolithic microwave integrated circuit process. IEEE Electron Device Lett. 2015, 36, 1004-1007. [CrossRef]

4. Luo, X.; Halder, S.; Curtice, W.R.; Hwang, J.C.M.; Chabak, K.D.; Dennis, E.; Dabiran, A.M. Scaling and high-frequency performance of AIN/GaN HEMTs. In Proceedings of the IEEE International Symposium on Radio-Frequency Integration Technology, Beijing, China, 30 November-2 December 2011. [CrossRef]

5. Vallabhaneni, A.K.; Chen, L.; Gupta, M.P.; Kumar, S. Solving nongray boltzmann transport equation in gallium nitride. J. Heat Transf. 2017, 139. [CrossRef]

6. Yalamarthy, A.S.; So, H.; Muñoz Rojo, M.; Suria, A.J.; Xu, X.; Pop, E.; Senesky, D.G. Tuning electrical and thermal transport in $\mathrm{AlGaN} / \mathrm{GaN}$ heterostructures via buffer layer engineering. Adv. Funct. Mater. 2018, 28. [CrossRef] 
7. Hao, Q.; Zhao, H.; Xiao, Y.; Kronenfeld, M.B. Electrothermal studies of GaN-based high electron mobility transistors with improved thermal designs. Int. J. Heat Mass Transf. 2018, 116, 496-506. [CrossRef]

8. Zhang, G.-C.; Feng, S.-W.; Zhou, Z.; Li, J.-W.; Guo, C.-S. Evaluation of thermal resistance constitution for packaged $\mathrm{AlGaN} / \mathrm{GaN}$ high electron mobility transistors by structure function method. Chin. Phys. B 2011, 20, 027202. [CrossRef]

9. Sarua, A.; Ji, H.; Hilton, K.P.; Wallis, D.J.; Uren, M.J.; Martin, T.; Kuball, M. Thermal boundary resistance between $\mathrm{GaN}$ and substrate in $\mathrm{AlGaN} / \mathrm{GaN}$ electronic devices. IEEE Trans. Electron Devices 2007, 54, 3152-3158. [CrossRef]

10. Cho, J.; Bozorg-Grayeli, E.; Altman, D.H.; Asheghi, M.; Goodson, K.E. Low thermal resistances at GaN-SiC interfaces for HEMT technology. IEEE Electron Device Lett. 2012, 33, 378-380. [CrossRef]

11. Freedman, J.P.; Leach, J.H.; Preble, E.A.; Sitar, Z.; Davis, R.F.; Malen, J.A. Universal phonon mean free path spectra in crystalline semiconductors at high temperature. Sci. Rep. 2013, 3. [CrossRef]

12. Cheng, Z.; Koh, Y.R.; Mamun, A.; Shi, J.; Bai, T.; Huynh, K.; Yates, L.; Liu, Z.; Li, R.; Lee, E.; et al. Experimental Observation of High Intrinsic Thermal Conductivity of AlN. Available online: https://arxiv.org/ftp/arxiv/ papers/1911/1911.01595.pdf (accessed on 10 April 2020).

13. Park, K.; Bayram, C. Impact of dislocations on the thermal conductivity of gallium nitride studied by time-domain thermoreflectance. J. Appl. Phys. 2019, 126. [CrossRef]

14. Liu, W.; Balandin, A.A. Thermal conduction in AlxGa1-xN alloys and thin films. J. Appl. Phys. 2005, 97, 1-6. [CrossRef]

15. Chatterjee, B.; Dundar, C.; Beechem, T.E.; Heller, E.; Kendig, D.; Kim, H.; Donmezer, N.; Choi, S. Nanoscale electro-thermal interactions in AlGaN/GaN high electron mobility transistors. J. Appl. Phys. 2020, 127. [CrossRef]

16. Lundh, J.S.; Chatterjee, B.; Song, Y.; Baca, A.G.; Kaplar, R.J.; Beechem, T.E.; Allerman, A.A.; Armstrong, A.M.; Klein, B.A.; Bansal, A.; et al. Multidimensional thermal analysis of an ultrawide bandgap AlGaN channel high electron mobility transistor. Appl. Phys. Lett. 2019, 115. [CrossRef]

17. Yang, F.; Dames, C. Mean free path spectra as a tool to understand thermal conductivity in bulk and nanostructures. Phys. Rev. B Condens. Matter Mater. Phys. 2013, 87, 1-12. [CrossRef]

18. Regner, K.T.; Wei, L.C.; Malen, J.A. Interpretation of thermoreflectance measurements with a two-temperature model including non-surface heat deposition. J. Appl. Phys. 2015, 118. [CrossRef]

19. Hua, C.; Minnich, A.J. Semi-analytical solution to the frequency-dependent Boltzmann transport equation for cross-plane heat conduction in thin films. J. Appl. Phys. 2015, 117. [CrossRef]

20. Regner, K.T.; Freedman, J.P.; Malen, J.A. Advances in studying phonon mean free path dependent contributions to thermal conductivity. Nanoscale Microscale Thermophys. Eng. 2015, 19, 183-205. [CrossRef]

21. Guo, Y.; Wang, M. Phonon hydrodynamics for nanoscale heat transport at ordinary temperatures. Phys. Rev. B 2018, 97, 1-27. [CrossRef]

22. Reisinger, M.; Tomberger, M.; Zechner, J.; Daumiller, I.; Sartory, B.; Ecker, W.; Keckes, J.; Lechner, R.T.T. Resolving alternating stress gradients and dislocation densities across AlxGa1-xN multilayer structures on Si(111). Appl. Phys. Lett. 2017, 111. [CrossRef]

23. Netzsch (Ed.) Thermoreflectance by Pulsed Light Heating Thermoreflectance-NanoTR/PicoTR. Available online: https://www.netzsch-thermal-analysis.com/de/produkte-loesungen/waerme-und-temperaturleitfaehigkeitsbestimmung/nanotrpicotr/ (accessed on 4 May 2020).

24. Fladischer, K.; Leitgeb, V.; Mitterhuber, L.; Keckes, J.; Sagmeister, M.; Carniello, S. Combined thermo-physical investigations of thin layers with Time Domain Thermoreflectance and Scanning Thermal Microscopy on the example of $500 \mathrm{~nm}$ thin, CVD grown tungsten. Thermochim. Acta 2019. [CrossRef]

25. Cahill, D.G. Analysis of heat flow in layered structures for time-domain thermoreflectance. Rev. Sci. Instrum. 2004, 75, 5119-5122. [CrossRef]

26. Yang, J.; Ziade, E.; Schmidt, A.J. Uncertainty analysis of thermoreflectance measurements. Rev. Sci. Instrum. 2016, 87, 1-11. [CrossRef] [PubMed]

27. Glassbrenner, C.J.; Slack, G.A. Thermal conductivity of silicon and germanium from $3^{\circ} \mathrm{K}$ to the melting point. Phys. Rev. 1964, 134, A1058. [CrossRef]

28. Corruccini, R.J.; Gniewek, J.J. Specific Heats and Enthalpies of Technical Solids at Low Temperatures; National Bureau of Standards: Washington, DC, USA, 1960. [CrossRef] 
29. Palankovski, V.; Quay, R. Analysis and Simulation of Heterostructure Devices; Springer: Wien, Austria, 2004. [CrossRef]

30. Danilchenko, B.A.; Paszkiewicz, T.; Wolski, S.; Jezowski, A.; Plackowski, T. Heat capacity and phonon mean free path of wurtzite GaN. Appl. Phys. Lett. 2006, 89. [CrossRef]

31. Mitterhuber, L.; Hammer, R.; Dengg, T.; Fladischer, K.; Spitaler, J. Thermal investigation of AlGaN-GaN multilayer structures. In Proceedings of the THERMINIC 2019-25th International Workshop on Thermal Investigations of ICs and Systems, Lecco, Italy, 25-27 September 2019. [CrossRef]

32. Slack, G.A.; Tanzilli, R.A.; Pohl, R.O.; Vandersande, J.W. The intrinsic thermal conductivity of AIN. J. Phys. Chem. Solids 1987, 48, 641-647. [CrossRef]

33. Abeles, B. Lattice thermal conductivity of disordered semiconductor alloys at high temperatures. Phys. Rev. 1963, 131, 1906-1911. [CrossRef]

34. Daly, B.C.; Maris, H.J.; Nurmikko, A.V.; Kuball, M.; Han, J. Optical pump-and-probe measurement of the thermal conductivity of nitride thin films. J. Appl. Phys. 2002, 92, 3820-3824. [CrossRef]

35. Shibata, H.; Waseda, Y.; Ohta, H.; Kiyomi, K.; Shimoyama, K.; Fujito, K.; Nagaoka, H.; Kagamitani, Y.; Simura, R.; Fukuda, T. High thermal conductivity of gallium nitride $(\mathrm{GaN})$ crystals grown by HVPE Process. Mater. Trans. 2007, 48, 2782-2786. [CrossRef]

36. Berg, W.T. The low temperature heat capacity of platinum. J. Phys. Chem. Solids 1969, 30, 69-72. [CrossRef]

37. Hopkins, P.E.; Norris, P.M.; Stevens, R.J. Influence of inelastic scattering at metal-dielectric interfaces. J. Heat Transf. 2008, 130, 022401. [CrossRef]

38. Stanley, C.M.; Estreicher, S.K. Phonon dynamics at an oxide layer in silicon: Heat flow and Kapitza resistance. Phys. Status Solidi Appl. Mater. Sci. 2019, 216,1-9. [CrossRef]

39. Hopkins, P.E.; Norris, P.M. Relative Contributions of inelastic and elastic diffuse phonon scattering to thermal boundary conductance across solid interfaces. J. Heat Transf. 2009, 131, 22402. [CrossRef]

40. Hopkins, P.E.; Duda, J.C.; Clark, S.P.; Hains, C.P.; Rotter, T.J.; Phinney, L.M.; Balakrishnan, G. Effect of dislocation density on thermal boundary conductance across GaSb/GaAs interfaces. Appl. Phys. Lett. 2011, 98. [CrossRef]

41. Swartz, E.T.; Pohl, R.O. Thermal boundary resistance. Rev. Mod. Phys. 1989, 61, 605-668. [CrossRef]

42. Stoner, R.J.; Maris, H.J. Kapitza conductance and heat-Flow between solids at temperatures from 50 to $300 \mathrm{~K}$. Phys. Rev. B 1993, 48, 16373-16387. [CrossRef]

43. Norris, P.M.; Hopkins, P.E. Examining interfacial diffuse phonon scattering through transient thermoreflectance measurements of thermal boundary conductance. J. Heat Transf. 2009, 131, 043207. [CrossRef]

44. Keune, W.; Hong, S.; Hu, M.Y.; Zhao, J.; Toellner, T.S.; Alp, E.E.; Sturhahn, W.; Rahman, T.S.; Roldan Cuenya, B. Influence of interfaces on the phonon density of states of nanoscale metallic multilayers: Phonon confinement and localization. Phys. Rev. B 2018, 98,1-16. [CrossRef]

45. Callaway, J. Model for lattice thermal conductivity at low temperatures. Phys. Rev. 1959, 113, $1046-1051$. [CrossRef]

46. Morelli, D.T.; Heremans, J.P.; Slack, G.A. Estimation of the isotope effect on the lattice thermal conductivity of group IV and group III-V semiconductors. Phys. Rev. B Condens. Matter Mater. Phys. 2002, 66, 1953041-1953049. [CrossRef]

47. Jugdersuren, B.; Kearney, B.T.; Queen, D.R.; Metcalf, T.H.; Culbertson, J.C.; Chervin, C.N.; Stroud, R.M.; Nemeth, W.; Wang, Q.; Liu, X. Thermal conductivity of amorphous and nanocrystalline silicon films prepared by hot-wire chemical-vapor deposition. Phys. Rev. B 2017, 96, 1-8. [CrossRef]

48. Chen, G. Size and interface effects on thermal conductivity of superlattices and periodic thin-film structures. J. Heat Transf. 1997, 119, 220-229. [CrossRef]

49. Peierls, R. Zur kinetischen Theorie der Wärmeleitung in Kristallen. Ann. Phys. 1929, 395, $1055-1101$. [CrossRef]

50. Klemens, P.G.; White, G.K.; Tainsh, R.J. Scattering of lattice waves by point defects. Philos. Mag. 1962, 7, 1323-1335. [CrossRef]

51. Wang, Z.; Alaniz, J.E.; Jang, W.; Garay, J.E.; Dames, C. Thermal conductivity of nanocrystalline silicon: Importance of grain size and frequency-dependent mean free paths. Nano Lett. 2011, 11, 2206-2213. [CrossRef]

52. Toberer, E.S.; Zevalkink, A.; Snyder, G.J. Phonon engineering through crystal chemistry. J. Mater. Chem. 2011, 21, 15843-15852. [CrossRef] 
53. Alekseeva, G.T.; Efimova, B.A.; Ostrovskaya, L.M.; Serebryannikova, O.S.; Tsypin, M.I. Thermal conductivity of solid solutions based on lead telluride. Sov. Phys. Semicond. 1971, 4, 1122-1125.

54. Dengg, T.; Razumovskiy, V.; Romaner, L.; Kresse, G.; Puschnig, P.; Spitaler, J. Thermal expansion coefficient of WRe alloys from first principles. Phys. Rev. B 2017, 96. [CrossRef]

55. Kresse, G.; Furthmüller, J. Efficient iterative schemes for ab initio total-energy calculations using a plane-wave basis set. Phys. Rev. B Condens. Matter Mater. Phys. 1996, 54, 11169-11186. [CrossRef]

56. Fan, Z.; Dong, H.; Harju, A.; Ala-Nissila, T. Homogeneous nonequilibrium molecular dynamics method for heat transport and spectral decomposition with many-body potentials. Phys. Rev. B 2019, 99, 1-9. [CrossRef]

57. Sondheimer, E.H. The mean free path of electrons in metals. Adv. Phys. 1952, 1,1-42. [CrossRef]

58. Beechem, T.E.; McDonald, A.E.; Fuller, E.J.; Talin, A.A.; Rost, C.M.; Maria, J.P.; Gaskins, J.T.; Hopkins, P.E.; Allerman, A.A. Size dictated thermal conductivity of GaN. J. Appl. Phys. 2016, 120. [CrossRef]

59. Hodges, C.; Anaya Calvo, J.; Stoffels, S.; Marcon, D.; Kuball, M. AlGaN/GaN field effect transistors for power electronics - Effect of finite GaN layer thickness on thermal characteristics. Appl. Phys. Lett. 2013, 103. [CrossRef]

(C) 2020 by the authors. Licensee MDPI, Basel, Switzerland. This article is an open access article distributed under the terms and conditions of the Creative Commons Attribution (CC BY) license (http://creativecommons.org/licenses/by/4.0/). 